\title{
Vivências com a Natureza: uma proposta de Educação Am- biental para o Uso Público em Unidades de Conservação ${ }^{1}$
}

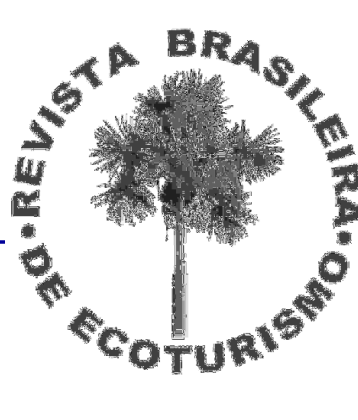

\author{
Fernando Protti Bueno
}

\section{RESUMO}

As Unidades de Conservação são consideradas espaços territoriais que instituídos pelo poder público tem por principal objetivo a proteção dos recursos naturais. Em função da manutenção de suas áreas conservadas, as Unidades de Conservação representam espaços propícios para a pesquisa científica, o uso sustentável e para as diferentes formas de lazer e turismo em contato com a natureza. A partir desse contexto, vislumbra-se a visitação em Unidades de Conservação como um importante instrumento para a conservação da natureza desses espaços, em função do incremento econômico, do investimento em pesquisas, do desenvolvimento de compreensões sobre as formas de vida e seus ciclos vitais, e dos hábitos e costumes das populações tradicionais, além do fomento de atividades turístico-recreativas. Pressupondo que o contato com a natureza possibilita a ampliação da consciência ambiental dos indivíduos sobre a atual situação de degradação dos recursos naturais e de suas potenciais formas de utilização pela sociedade, evidencia-se a importância da realização de atividades de Educação Ambiental atreladas à visitação / uso público de Unidades de Conservação. Assim, essa pesquisa teve por objetivos caracterizar e analisar a técnica do 'Aprendizado Sequencial' enquanto uma possível proposta metodológica de Educação Ambiental, a ser implantada e desenvolvida para o uso público em Unidades de Conservação. Para tanto, adotaram-se como procedimentos metodológicos o método indutivo com abordagem qualitativa, as técnicas de pesquisa bibliográfica, documental e de observação assistemática para coleta e análise dos dados. Por fim, a proposta metodológica desenvolvida pela técnica do aprendizado sequencial possibilita ao indivíduo aprender e desenvolver características de transformação interior, baseadas na afetividade e na experiência direta com a natureza, que elucidam os valores necessários para uma efetiva conservação da natureza, auxiliando assim, o planejamento e o manejo do uso público nas Unidades de Conservação.

PALAVRAS-CHAVE: Educação Ambiental, Uso público, Unidades de Conservação. 


\section{Sharing with Nature: A Proposal by Environmental Education for Public Use in Protected Areas}

\section{ABSTRACT}

The conservation areas are considered areas of land that, instituted by the government, have, as the principal objective, the protection of natural resources. Because of the maintenance of the conservation areas, the Protected Areas represent appropriate spaces for the scientific research, sustainable use and the different forms of leisure and tourism in contact with nature. From this context, we consider the visitation in Protected Areas as an important tool for the conservation of the nature of these spaces, due to the increase in the economy, the investment in research, the development of understandings about of the ways of life and their vital cycles, and the habits and customs of local people, as well as the encouragement of tourismrecreational activities. Assuming that the contact with nature allows the expansion of environmental awareness of individuals about the current situation of natural resource degradation and its potential forms of use by the society, the importance of carrying out Environmental Education activities tied to the visitation / use public in protected areas is highlighted. Thus, the objective of this study was to characterize and analyze the technique of 'Flow Learning' as a possible methodological proposal for Environmental Education, to be implemented and developed for public use in protected areas. Therefore, the instruments adopted were the inductive method with a qualitative approach, and the techniques of literature review, documental, and the systematic observation to collect and analyze data. Finally, the proposed methodology suggested by the technique of 'Flow Learning' allows individuals to learn and develop characteristics of inner transformation, based on affection and on direct experience with nature, what elucidated the necessary values for effective conservation, thereby assisting the planning and management of public use in Protected Areas.

KEYWORDS: Environmental Education, Public Use , Protected Areas.

\section{Introdução}

A crescente busca por áreas naturais, principalmente as protegidas ou então àquelas denominadas Unidades de Conservação, promovida pela motivação do contato com a natureza retoma o chamado 'mito do eterno retorno' ou mesmo o reencontro com o 'paraíso perdido', onde os elementos naturais estão e são valorizados, por meio do estabelecimento de uma relação 'harmônica' e de um sentimento de felicidade nos homens em relação à natureza. Entretanto, essa busca por áreas naturais não 
é algo novo, parece estar no subconsciente humano como sendo uma de suas necessidades básicas e imediatas, visto que o ser humano detém a curiosidade e a nostalgia pela busca de algo novo ou inédito, na tentativa de se reaproximar da natureza. Assim, na atualidade esses espaços tem sido buscados porque tornam-se propícios ao desenvolvimento de atividades de lazer, de educação e de contato com a natureza (CASCINO, 1998; PIRES, 2002; RODRIGUES, 2003; TAKAHASHI, 2004).

Além dessa procura por áreas naturais, torna-se necessário atentar que as mesmas detêm recursos naturais considerados raros ou únicos, fato que as têm tornado e as têm posicionado entre os principais atrativos turísticos de determinadas localidades, que se traduziu como uma tendência para o desenvolvimento da área de viagens e turismo (OMT, 2003). Entretanto, se tem ciência de que estas áreas, normalmente e de acordo com suas características bióticas, são consideradas frágeis e suscetíveis aos constantes impactos ocasionados pela sua utilização / visitação, tornando-se necessário compreender o ciclo evolutivo dos recursos naturais, para o manejo adequado perante as suas características de uso.

Mesmo sendo considerado um dilema para as Unidades de Conservação, temse como pressuposto a possibilidade de conciliar o uso recreativo e educativo com a conservação da natureza dessas áreas, afinal, dentre as possíveis justificativas para a criação das Unidades de Conservação está o uso público, bem como, a determinação de tornar favoráveis as condições para a promoção da educação e da interpretação ambiental, da recreação e do contato com a natureza, e do turismo ecológico, estabelecida pelo SNUC - Sistema Nacional de Unidades de Conservação (BRASIL, 2000).

Assim, de acordo com cada uma das categorias de Unidades de Conservação (unidades de proteção integral e unidades de uso sustentável) e suas diferentes categorias de manejo, previstas no SNUC, bem como, de acordo com seus objetivos, as atividades permitidas e suas proibições, há que se considerar o desenvolvimento de programas de uso público, devidamente planejados, que contemplem a recreação e a Educação Ambiental, como formas de conciliar o alcance do objetivo de conservação da natureza com o uso público das Unidades de Conservação.

Pressupondo o potencial da Educação Ambiental para a conservação da natureza, especialmente considerando o potencial educativo do contato dirigido com a natureza, a presente pesquisa teve por objetivos a caracterização e a análise da técnica do Aprendizado Sequencial enquanto uma possível proposta metodológica de Educação Ambiental implantada e desenvolvida ao uso público de Unidades de Conservação.

Adotou-se a premissa de que o aprendizado sequencial compreende uma forma metodológica sistematizada de Educação Ambiental possível de ser aplicada a diferentes atividades, entre estas as atividades turístico-recreativas desenvolvidas em áreas naturais, configurando-se assim como um processo educativo passível de ser realizado no âmbito do lazer, por meio da promoção de experiências diretas com a natureza. 
No intuito de atingir os objetivos dessa pesquisa adotaram-se como procedimentos metodológicos o método indutivo, com abordagem qualitativa, que permitiu a elaboração de uma síntese teórica acerca do aprendizado sequencial e da Educação Ambiental, a partir da qual desenvolveu-se a análise da pertinência da aplicação desses processos educativos no planejamento e desenvolvimento de atividades turísticorecreativas no âmbito do uso público em Unidades de Conservação, com vistas à agregar nessas atividades um potencial educativo diretamente ligado ao desenvolvimento de valores e de mudanças de atitudes nos visitantes, alinhadas à conservação da natureza (LAKATOS; MARCONI, 2007).

Também se adotaram como procedimentos metodológicos as técnicas de pesquisa bibliográfica, documental e observação assistemática ${ }^{2}$ para coleta de dados, além da técnica de análise documental, para a análise dos dados coletados (LAKATOS; MARCONI, 2007; RICHARDSON, 1999).

\section{Uso público e Educação Ambiental em Unidades de Conservação}

Ao considerar a possibilidade de integração entre o uso público, normalmente orientado por processos educativos, e a conservação da natureza em Unidades de Conservação, se torna salutar a retomada ao ponto de partida, ou seja, a criação, a implantação e o manejo dessas áreas, já que se pressupõe que está integração somente seja possível a partir da conciliação entre uma série de fatores envolvidos em um processo de planejamento ao uso e gestão destas unidades.

As áreas naturais protegidas são consideradas espaços físicos demarcados para o cumprimento do objetivo primário de proteção (preservação e conservação) de relevantes recursos naturais, tendo seu surgimento em sua concepção moderna a partir de 1872 com a criação do Yellowstone National Park, nos Estados Unidos, que visava "[...] a proteção da natureza para o usufruto dos seus valores (naturais, estéticos, culturais e éticos) pelas gerações atuais e futuras [...]" (MILANO, 1997, p.151).

A partir desta iniciativa e do conceito básico vigente, várias outras áreas naturais foram criadas ao redor do mundo, se adequando as realidades e necessidades de cada país, bem como aos processos pelos quais cada instituição formaria para proceder com o gerenciamento destas áreas. A evolução relativa à criação e ao gerenciamento das áreas naturais protegidas foi notadamente marcada pelo avanço no campo da ciência e pelos diferentes intuitos e necessidades colocadas pela sociedade, formulando-se então, distintas categorias de manejo, postuladas como diferentes tipos de áreas naturais em virtude de seus objetivos de proteção da natureza (BRASIL, 2007a; MILANO, 1997).

Diante da elaboração das categorias de manejo, cada área natural protegida passa a compor a estrutura de um sistema planejado para a proteção da natureza, 
oferecendo condições para o surgimento das Unidades de Conservação, que detinham os seus próprios objetivos aplicados às condições biofísicas, ecológicas e sócio-econômicas de uma determinada localidade (MILANO, 1997).

Atualmente sendo uma das tipologias previstas no modelo brasileiro (SNUC Sistema Nacional de Unidades de Conservação), a criação das Unidades de Conservação deriva do conceito básico dos parques nacionais americanos, tendo seu marco em 1937 com a criação do Parque Nacional de Itatiaia e sendo até então, uma das principais estratégias para a proteção da biodiversidade. Entretanto, sua formulação enquanto sistema, bem como sua discussão e práxis de criação e de proteção da natureza percorreram todo o período histórico da república brasileira ${ }^{3}$ (BRASIL, 2007a; MEDEIROS, 2006).

Instituído a partir do ano 2000 e constituído pelas Unidades de Conservação federais, estaduais e municipais, o SNUC define unidade de conservação como sendo o conjunto do espaço físico do território, geograficamente delimitado, e os relevantes recursos ambientais nele inseridos, sob o qual serão aplicados objetivos e garantias de proteção da natureza. A partir do estabelecido, as Unidades de Conservação estão subdivididas em dois grupos e compostos por suas diferentes categorias de manejo, a saber:

- Unidades de Proteção Integral, que dispõe como objetivo básico a preservação da natureza, admitindo-se apenas o uso indireto dos seus recursos ambientais: Estação Ecológica; Reserva Biológica; Parque Nacional; Monumento Natural; e Refúgio de Vida Silvestre.

- Unidades de Uso Sustentável, que dispõe enquanto objetivo básico a adequada conciliação entre o uso de partes dos seus recursos ambientais com a conservação da natureza: Área de Proteção Ambiental; Área de Relevante Interesse Ecológico; Floresta Nacional; Reserva Extrativista; Reserva de Fauna; Reserva de Desenvolvimento Sustentável; e Reserva Particular do Patrimônio Natural (BRASIL, 2000).

Esse Sistema determina dentre os seus objetivos aquele que se torna determinante para o foco dessa pesquisa, pois visa favorecer adequadas condições para a promoção e o incentivo "[...[ a educação e interpretação ambiental, a recreação em contato com a natureza e o turismo ecológico ${ }^{4}[\ldots]$ ]"(BRASIL, 2000).

Notadamente, desde sua criação, as Unidades de Conservação e mais especificamente algumas categorias, já demonstravam especial atenção as questões do lazer, da recreação, do turismo e da Educação Ambiental nestas áreas naturais. Exemplo disso pode ser obtido em Medeiros (2006, p. 50) quando cita que já nas primeiras linhas do decreto de criação do Parque Nacional de Itatiaia, já estaria representada as pretensões para atender "[...] às [finalidades] de ordem turística, que se apresentem 
em condições de fazer do Parque um centro de atração para viajantes, assim nacionais como estrangeiros".

Outro exemplo que facilita a visualização da associação e/ou relação entre turismo e Educação Ambiental são as vinculações atribuídas pelos diferentes instrumentos instaurados pelo poder público como forma de política pública, dentre estas estão as Diretrizes para uma Política Nacional de Ecoturismo (DPNE) e a Política Nacional de Educação Ambiental (PNEA). Respectivamente criadas em 1994 e 1999, delineiam-se de maneira a nomearem-se de modo invertido como importantes ferramentas para o controle dos visitantes e para o alcance do objetivo de conservar a natureza (BRASIL, 1994; BRASIL, 1999).

Entretanto, a partir então, da tentativa de garantir a efetiva proteção da natureza, como forma de valorar ou resguardar os recursos naturais, cada uma das categorias de Unidades de Conservação passou a adotar critérios e estratégias, bem como regulamentar permissões e restrições quanto ao uso de seus espaços (MEDEIROS, 2006). Assim, segundo o SNUC todas as categorias de Unidades de Conservação admitem visitação pública, com regras mais ou menos restritivas, como por exemplo, o caso das Estações Ecológicas e Reservas Biológicas, que são as categorias mais restritivas quanto a presença e ao uso humano, pois apenas permitem a visitação pública com fins educacionais. Já as demais categorias, admitem a visitação pública de acordo com o estabelecido em seus planos de manejo (BRASIL, 2007b).

Acerca do uso público em Unidades de Conservação, Takahashi et al (1997) salientam que em grande parte das unidades, as atividades turístico-recreativas estão restringidas as caminhadas em trilhas e a contemplação da natureza, como formas mais emblemáticas do lazer e da educação em contato com a natureza. Por outro lado, Aoki e Andrade (1997), Takahashi et al. (1997), e Brasil (2006), ao mesmo tempo que identificam uma série de atividades, inseridas no contexto das atividades radicais ${ }^{5}$, tendo a natureza como a principal motivação, sendo desenvolvidas enquanto uso público em Unidades de Conservação, também fazem recomendações para um melhor ordenamento destas atividades, na tentativa de conciliar a satisfação dos visitantes - maximizando sua experiência, com a conservação na natureza - minimizando os impactos nocivos, prioritariamente aos aspectos ambientais.

Considerando o significativo aumento da visitação nas unidades e as múltiplas variedades de públicos visitantes e de possibilidades para o desenvolvimento de atividades turístico-recreativa, Takahashi et al . (1997) questionam o estímulo ao desenvolvimento de determinados tipos de atividades em função, prioritariamente, dos impactos provocados no ambiente natural, principalmente, quando se tratam de Unidades de Conservação sem adequadas condições de infra-estrutura, recursos humanos e sem um eficiente processo de planejamento para a gestão da visitação na unidade.

Assim, também diante da crescente procura por novos e diferentes usos, conjugado às mudanças de concepção sobre o planejamento e o gerenciamento da conservação da natureza, as Unidades de Conservação passam a investir no turismo e 
na recreação, como forma de estreitar o contato da sociedade com a natureza, bem como forma de servir como um veículo para a Educação Ambiental, ao passo que esta favorece certas condições para o manejo dos recursos ambientais (BRASIL, 2007b; BRASIL, 2008; TAKAHASHI et al., 1997).

Entretanto, esta crescente visitação ocorre de forma desordenada, muitas vezes por não dispor de um adequado planejamento, que coloca em risco a qualidade ambiental dos recursos afetados, assim, necessita desenvolver processos para ordenar, orientar e controlar o manejo e a gestão da visitação nas Unidades de Conservação (MILANO, 1997; TAKAHASHI, 2004).

Para Milano (1997, p. 152-153) o planejamento das Unidades de Conservação pode ser considerado como "[...] o estudo das alternativas de manejo aplicáveis a uma determinada área [...]", ou ainda, como "[...] nome dado ao processo de identificação e ordenamento de fatores e meios, aí incluídos processos e tempo, necessários ao alcance dos objetivos previamente definidos [...] significa tratar do futuro, definir ações e identificar os agentes ou atores dessas ações".

Assim, a apresentação de sínteses sobre o conceito de planejamento, contudo, parece não facilitar uma questão crucial que se coloca para as ações que visam a proteção da natureza nas Unidades de Conservação, que se explicita, portanto, no âmbito da prática, que é a questão da "[...] real função do planejamento das Unidades de Conservação dentro do contexto de utilidade que se espera desse procedimento, entendido em suas funções e dinâmicas plenas" (MILANO, 1997, p. 152).

Com isso, a iminente necessidade de maior reflexão sobre esta questão se faz presente, principalmente tendo-se em vista o aumento da demanda por atividades turístico-recreativas em Unidades de Conservação e o potencial que essas atividades reservam enquanto processos educativos não-formais, que tem um papel importante nos processos de orientação da visitação pública, na sensibilização dos visitantes/ turistas para os valores da natureza e no delineamento dos programas de uso público e, primordialmente, na conservação / proteção da natureza.

Assim sendo, cabe a cada unidade de conservação formular programas e subprogramas de uso público, inseridos em seus planos de manejo, com vistas à estruturação e qualificação da visitação, na tentativa de superar a visão de que o incremento da visitação possa comprometer os objetivos de conservação. Para tanto, há a necessidade de um processo de planejamento, de investimentos em infra-estruturas básicas, de apoio e turísticas, de capacitação de pessoas, de adequadas formas de controle e gestão, de participação e valorização da população local, e de benefícios econômicos que promovam emprego e renda as comunidades, bem como garantam a manutenção da biodiversidade por incremento da pesquisa científica, entre outros (BRASIL, 2007b).

Como forma de propor indicações básicas ao processo de planejamento da visitação em Unidades de Conservação pontua-se a necessidade de efetuar um diagnóstico da realidade do local, como forma de caracterizar a diversidade de contextos 
ambientais, sociais e econômicos, bem como a infra-estrutura, os recursos humanos e as possíveis possibilidades de atividades turístico-recreativas a serem desenvolvidas. Como uma das formas de esforço para a proteção da natureza caberá as Unidades de Conservação implantarem processos e ações preventivas realizadas na forma de Educação Ambiental. Contudo, o potencial educativo das atividades turísticorecreativas em contato com a natureza será favorecido a medida que tais atividades estejam baseadas nos princípios e objetivos da Educação Ambiental, bem como nos instrumentos de controle e monitoramento da visitação.

Cabe salientar que a metodologia de Educação Ambiental, Aprendizado Sequencial, aqui apresentada representa uma das possíveis formas estruturadas de desenvolvimento e aplicação da Educação Ambiental em diferentes contextos, entre estes no uso público de Unidades de Conservação, tendo como intuito a composição de um processo educativo relacionado ao aprendizado proporcionado pelas sensações e pelas experiências advindas do contato com a natureza que, supostamente, modificam os comportamentos e, consequentemente, as atitudes dos indivíduos perante a natureza perfazendo assim, o possível benefício de conservação da natureza dessas áreas visitadas.

\section{Resultados e discussões - a proposta do Aprendizado Sequencial}

As possíveis experiências que se pode ter com a natureza fizeram o naturalista Joseph Cornell, profundo conhecedor de percepções na natureza e de educação ao ar livre, elaborar uma metodologia considerada original, que auxilia e, ao mesmo tempo, trata de maneira profunda a interação que se pode ter com a natureza (MENDONÇA, 2000).

Joseph Cornell difundiu seu trabalho e sua metodologia em palestras e workshops por meio da Sharing Nature Foundation (1979), com sede nos Estados Unidos e representada em vários países e dentre eles, o Brasil, sendo representada desde 1996 por intermédio do Instituto Romã e de sua coordenadora Rita Mendonça (FURIHATA, 2006; INSTITUTO ROMÃ, 2008a, 2008b; MENDONÇA, 2000 e 2006; SHARING NATURE FOUNDATION, 2008c).

A Sharing Nature Foundation e suas representações se dedicam a auxiliar as pessoas de diferentes faixas etárias a ter uma experiência única, alegre e inspiradora, de união e harmonia com todo tipo de vida, para isso, se utiliza de criativas atividades na natureza para ampliar a consciência de que as pessoas realmente podem alterar sua maneira de olhar e de se relacionar com o mundo à sua volta, basta que tenham a oportunidade de experienciar a natureza de maneira mais profunda (FURIHATA, 2006; SHARING NATURE FOUNDATION, 2008a).

Para tanto, a Sharing Nature criou um método estruturado em fluxos de aprendizado, denominado 'Aprendizado Sequencial' ${ }^{6}$ para trabalhar com a sensibilidade das pessoas e com as complexas relações humanas provenientes das mesmas, vislum- 
brando sempre a possibilidade de proporcionar as pessoas experiências profundas com a natureza a partir de sua estratégia de ensino, que consiste na escolha adequada de atividades lúdicas, como dinâmicas e jogos, a serem desenvolvidas em áreas naturais protegidas. Essas áreas se tornam privilegiadas, pois proporcionam experiências mais profundas de interiorização e imersão dos indivíduos participantes (MENDONÇA, 2006).

Cornell (1997) considera o aprendizado sequencial como uma das maneiras pela qual a Educação Ambiental organiza suas atividades com o intuito de proporcionar experiências puramente positivas com a natureza, que possibilitam ao indivíduo praticante penetrar de maneira completa no espírito do mundo natural, auxiliando assim, a descoberta interna do profundo sentimento de pertinência e compreensão relacionado a esse mundo. O autor afirma ainda que o desenvolvimento de sentimentos de afetividade e de preocupação para consigo, com os outros, bem como, para com o ambiente natural e para os demais seres que nos cercam, é a base para a construção de um processo educativo, pois caso contrário, as pessoas nunca serão tocadas de maneira profunda.

E, isso, poderá ocasionar uma interferência positiva na compreensão que as pessoas possuem em relação à conservação das áreas naturais, pois esse entendimento está impregnado na cultura da sociedade, por isso, cada país membro da Sharing Nature deve atentar e adaptar a metodologia do aprendizado sequencial às características culturais de sua população. Assim, a descrição dessa proposta vislumbra e indica a necessidade de adaptação dessa metodologia de acordo com cada realidade a ser trabalhada, como por exemplo, as categorias de Unidades de Conservação (proteção integral ou uso sustentável), as características de seu uso público, os programas de manejo estabelecidos (uso público, Educação Ambiental, recreação etc.), o tipo de público visitante (visitantes ou turistas), o tipo de atividade desenvolvida (trilhas guiadas), entre outras (MENDONÇA, 2000, 2006).

Assim, ao desenvolver o aprendizado sequencial, Joseph Cornell pensou em estabelecer e proporcionar uma melhor relação dos indivíduos com a natureza, pois ao longo de suas experiências com a natureza percebeu que havia uma sequência a ser trabalhada para que as atividades fossem mais produtivas, assim, concluiu que as pessoas reagiam favoravelmente a uma sequência determinada, posteriormente por ele, em função desta se harmonizar a determinados aspectos da natureza humana. Assim, considerou o aprendizado sequencial como um simples, porém, poderoso sistema de ensino baseado em princípios universais de consciência e de como as pessoas aprendem por meio de experiências (CORNELL, 1997; SHARING NATURE FOUNDATION, 2008b).

Em função disso, o método traz em sua proposta metodológica a realização de dinâmicas e jogos, organizados e direcionados perante uma sequência de 04 estágios (figura 01) - despertar do entusiasmo, concentrar a atenção, dirigir a experiência e compartilhar a inspiração - desenvolvidos de forma sutil, gradativa e divertida, com a 
intenção de criar um fluxo de energia, que vá de um estado de maior agitação para um estado de maior concentração da atenção e envolvimento, sendo que esses estágios fluem de um para o outro de maneira suave e natural, configurando assim, um processo educativo, onde o indivíduo passa pelos diferentes estágios e alcança as estruturas mentais proporcionadas pelas experiências diretas e profundas com a natureza (CORNELL, 1997; INSTITUTO ROMÃ, 2008b).

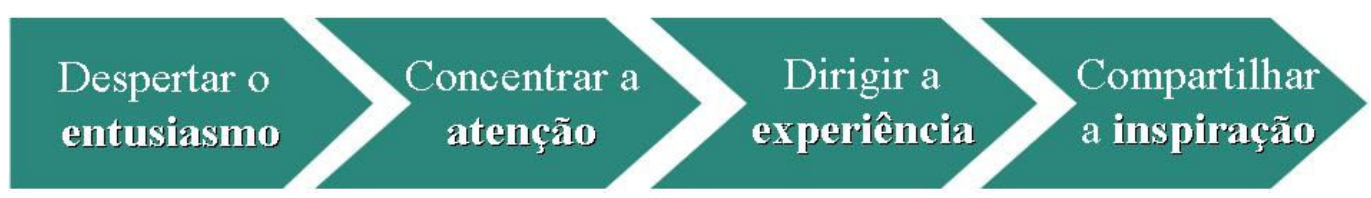

Figura 01 - Fluxo dos estágios

Fonte: confeccionado a partir de Cornell $(1996,1997,2005,2008)$

Relembra-se que a sua estrutura e dinâmica são extremamente flexíveis e adaptáveis, não se tratando de um sistema rígido que aplica as atividades sempre da mesma forma. Seus estágios não são estagnados e, por isso, fluem entre si, mas sempre mantendo as suas características principais, assim, o aprendizado sequencial possibilita a adequação de suas atividades para com a situação e o espaço em que o grupo se encontra, objetivando proporcionar uma significativa experiência com a natureza ${ }^{7}$.

O estágio 1 - 'Despertar o entusiasmo', é marcado pela diversão e pelo desenvolvimento de atividades que geram um intenso fluxo de energia, no sentido de haver um crescente interesse por aquilo que está sendo feito, assim, tem também a intenção de tornar o grupo homogêneo, no sentido dos graus de agitação e de consciência de grupo. Depois de entusiasmar, relaxar e captar a atenção dos participantes, os mesmos estarão eufóricos em função do divertimento das atividades do estágio 1 . Assim, o estágio 2 - 'Concentrar a atenção', conduz o entusiasmo na direção de uma atenção mais refinada, somente assim, será possível perceber a natureza e, ao mesmo tempo, dispor de calma, atenção e entusiasmo. Alguns grupos demandam um maior tempo para se concentrarem, assim, para ter certeza de quando iniciar o estágio 3 , o educador deve-se perguntar se o grupo já estaria preparado e concentrado para as atividades mais sensíveis, para uma 'Experiência direta'. Nesse terceiro estágio, o intuito é experimentar o contato direto com a natureza, abrir o coração das pessoas e intensificar um ou mais sentidos, para que os participantes possam descobrir um íntimo e profundo sentimento de pertencimento e compreensão. E por fim, o estágio 4 'Compartilhar a inspiração' é o momento em que os integrantes do grupo estão calmos, alegres e sensíveis a ouvir e contar (compartilhar) suas estórias, seus sentimentos, suas emoções etc. Agora é o momento propício para a inserção de atividades que contemplem o lado bonito e tocante da natureza. Nessas atividades de encerramento, o intuito é a consolidação da experiência proporcionada por uma vivência com a natureza, no sentido de ficar marcada no coração e na memória de cada participante (CORNELL, 1996, 1997, 2005 e 2008; MENDONÇA, 2000 e 2006). 
Contudo, como fundamentos dessa metodologia há a crença de que o aprendizado efetivo deva incluir e, por vezes até priorizar, a vivência e a experiência, sendo que apenas as transmissões de informações, por mais importantes que sejam não são suficientes para promover o aprofundamento, o enraizamento e o estímulo às mudanças de comportamentos. Nesse sentido, salienta-se que o aprendizado proporcionado por meio da experiência não é algo novo, mas a novidade dessa técnica está baseada nos diferentes estágios que a compõe, pois auxiliam os indivíduos a alcançarem uma estrutura mental ocasionada pelo potencial que a experiência direta e profunda permite (quadro 01) (CORNELL, 1997; INSTITUTO ROMÃ, 2008b; MENDONÇA, 2000, 2006).

Quadro 1 - Quadro do aprendizado sequencial

\begin{tabular}{|c|c|}
\hline ESTÁGIO 1 : Despertar o Entusiasmo & ESTÁGIO 2 : Concentrar a atenção \\
\hline Qualidade: Divertimento e Vivacidade & Qualidade: Receptividade \\
\hline $\begin{array}{l}\text { Vantagens: } \\
\text { - } \quad \text { Desenvolve o gosto de brincar; } \\
\text { - } \quad \text { Cria um ambiente de entusiasmo e de } \\
\text { envolvimento; } \\
\text { - } \quad \text { Incentiva um alto grau de atenção e } \\
\text { supera a passividade; } \\
\text { - } \quad \text { Concentra a atenção (reduz problemas } \\
\text { - } \quad \text { Cria uma boa dinâmica de grupo; } \\
\text { - } \quad \text { Proporciona direção e estrutura; } \\
\text { - } \quad \text { Prepara para as atividades mais sensí- } \\
\text { veis dos estágios seguintes. }\end{array}$ & $\begin{array}{l}\text { Vantagens: } \\
\text { - } \quad \text { Aumenta o nível de atenção; } \\
\text { - } \quad \text { Aumenta a percepção por meio da a- } \\
\text { tenção concentrada; } \\
\text { - } \quad \text { Canaliza de modo positivo o entusias- } \\
\text { mo gerado no Estágio 1; } \\
\text { - } \quad \text { Desenvolve habilidades perceptivas; } \\
\text { - } \quad \text { Tranquiliza a mente; } \\
\text { Desenvolve receptividade para experi- } \\
\text { ências mais sensíveis com a natureza; }\end{array}$ \\
\hline ESTÁGIO 3 : Dirigir a experiência & ESTÁGIO 4 : Compartilhar a Inspiração \\
\hline Qualidade: Absorção & Qualidade: Idealismo \\
\hline $\begin{array}{l}\text { Vantagens: } \\
\text { - } \quad \text { Facilita o aprendizado por meio de des- } \\
\text { cobertas pessoais; } \\
\text { - } \quad \text { Proporciona compreensão direta, expe- } \\
\text { riencial e intuitiva; } \\
\text { - Incentiva a admiração, a empatia e o } \\
\text { amor; } \\
\text { Desenvolve comprometimento pessoal } \\
\text { com os ideais ecológicos. }\end{array}$ & $\begin{array}{l}\text { Vantagens: } \\
\text { - } \quad \text { Aclara e fortalece as experiências pes- } \\
\text { soais; } \\
\text { - } \quad \text { Eleva o estado de espírito; } \\
\text { - } \quad \text { Introduz modelos inspiradores da vida } \\
\text { de outras pessoas; } \\
\text { - } \quad \text { Reforça o sentido de união entre os } \\
\text { participantes e aproxima o grupo; }\end{array}$ \\
\hline
\end{tabular}

Fonte: adaptado a partir de Cornell (1997, p. 46-47) 
Assim, o aprendizado sequencial tem o poder de auxiliar as pessoas a esquecerem as suas preocupações, permitindo que elas se descontraiam, se divirtam e apreciem a natureza, sugerindo que o aprendizado seja por inteiro (corpo e mente), pois o método é, ao mesmo tempo, pedagógico e terapêutico, sendo que diante desse processo (dos estágios) o indivíduo acalma a mente e realiza melhor suas atividades, aprendendo a ouvir, a respeitar os outros e a refletir sobre suas necessidades e seus desejos (CORNELL, 1997; INSTITUTO ROMÃ, 2008b; MENDONÇA, 2000, 2006).

Mediante a apresentação da estrutura e do funcionamento da metodologia do aprendizado sequencial, o que se procurou demonstrar é que o contato com a natureza realizado por meio de um processo educativo sistematizado pode possibilitar o alcance dos objetivos da Educação Ambiental, conforme pontua Dias (1993, 2000), o desenvolvimento da consciência (processo de sensibilização e conscientização), do conhecimento e compreensão, do comportamento, por valores e atitudes, de habilidades e da ação participativa. E, assim, ao mesmo tempo promove uma experiência significativa e reconfortante ao visitante das Unidades de Conservação. Entretanto, isso só é possível a partir do momento em que a visita a esta unidade seja planejada de acordo com o que prevê os programas inseridos em seu plano de manejo.

\section{Conclusões}

O programa de uso público, bem como o programa de Educação Ambiental em Unidades de Conservação, mediante as propostas desenvolvidas por meio do seu planejamento e do plano de manejo necessitam implantar formas educativas que realmente ofereçam aos visitantes momentos de contato direto com a natureza e momentos de reflexão acerca das questões ambientais.

Pressupondo que grande parte do que se realiza enquanto Educação Ambiental em Unidades de Conservação não consegue atingir o ponto de sensibilização desenvolvendo as atividades aos visitantes do ponto de vista meramente contemplativo ou puramente informativo - necessitam-se então, de formas específicas de Educação Ambiental que fomentem a sensibilização e a reflexão, como formas de um processo de transformação crítica, nos visitantes. Somente a partir de processos educativos, potencializados por meio de metodologias de Educação Ambiental é que se podem alcançar os objetivos desenvolvidos pelo SNUC, bem como os objetivos da Educação Ambiental.

Assim, o planejamento e o desenvolvimento de processos educativos por meio de atividades turístico-recreativas no âmbito das Unidades de Conservação são passíveis de comporem os critérios estabelecidos pelas diferentes categorias de manejo, bem como pelos planos de manejo e seus programas de uso público, conciliando assim, o uso público com a proteção da natureza.

Isto se deve ao fato desse contato dirigido com a natureza ser permeado por 
uma estrutura sistematizada, como por exemplo, a estrutura do aprendizado sequencial, baseada no fluxo de seus estágios, que proporciona a sensibilização de indivíduos em prol da conservação das áreas naturais e estimula a mudança de comportamentos por meio das novas visões de mundo, estabelecidas nas experiências diretas com a natureza. Dessa forma, os programas de Educação Ambiental em Unidades de Conservação poderiam auxiliar de maneira mais direta e educativa o lazer da população local e o turismo dos visitantes.

A partir dessas considerações, enfatiza-se que como toda atividade humana desenvolvida no âmbito das Unidades de Conservação também há a necessidade de que possa ser monitorada, como forma de verificar e avaliar o grau de impactos nocivos causados prioritariamente nos aspectos ambientais. Pressupõe-se que por se tratar de uma atividade que apenas utiliza a natureza enquanto cenário para o desenvolvimento e a aplicação de atividades lúdico-recreativas, seja considerada de baixo impacto, ocasionando de maneira branda e remediável apenas o pisoteio, a compactação e a abertura de trilhas secundárias.

Por fim, acredita-se que a forma de Educação Ambiental, prioritariamente o Aprendizado Sequencial, tem a possibilidade de auxiliar a gestão das Unidades de Conservação no monitoramento do impacto, já que são atividades de baixo impacto, bem como ser uma das formas de manejo e orientação dos visitantes, tornando-se assim uma importante ferramenta para a gestão, para o monitoramento e para o manejo do uso público, estritamente com características educativas, ou seja, visitas voltadas exclusivamente para contemplação e o contato direto com a natureza, em Unidades de Conservação.

\section{Referências Bibliográficas}

AOKI, H.; ANDRADE, W.J. Programa de uso público e seu papel na conservação da natureza. In: CONGRESSO BRASILEIRO DE UNIDADES DE CONSERVAÇÃO, I, 1997, Curitiba - Paraná. Anais... Curitiba: Unilivre, vol. I, 1997, p. 370-377.

BRASIL. Lei n. 9.985, de 18 de julho de 2000. Regulamenta o art. 225, § 10, incisos I, II, III e VII da Constituição Federal, institui o Sistema Nacional de Unidades de Conservação da Natureza e dá outras providências. Diário Oficial da União: República Federativa do Brasil: Poder Legislativo, Brasília, DF, 18 julho 2000. Disponível em: <http://www.planalto.gov.br/ccivil 03/LEIS/L9985.htm>. Acesso em: 05 ago. 2009.

BRASIL. Lei $n^{\circ}$ 9.795, de 27 de abril de 1999. Dispõe sobre a Educação Ambiental, institui a Política Nacional de Educação Ambiental e dá outras providências. Diário Oficial da União: República Federativa do Brasil: Poder Legislativo, Brasília, DF, 27 abril 1999. Disponível em: <https://www.planalto.gov.br/ccivil 03/leis/19795.htm>. Acesso em: 05 ago. 2009. 
BRASIL. Ministério da Indústria, Comércio e Turismo. Ministério do Meio Ambiente. Diretrizes para uma política nacional de ecoturismo. Brasília, DF: EMBRATUR/ IBAMA, 1994.

BRASIL. Ministério do Meio Ambiente. Diretrizes para visitação em Unidades de Conservação. Brasília: MMA, 2006. Disponível em: <http://www.mma.gov.br/ estruturas/sbf2008 dap/ publicacao/149 publicacao26022009041254.pdf>. Acesso em: 16 ago. 2007.

BRASIL. Ministério do Meio Ambiente. Instituto Chico Mendes de Conservação da Biodiversidade. Unidades de Conservação do Brasil. Brasília: MMA, 2007a.

BRASIL. Ministério do Meio Ambiente. Instituto Chico Mendes de Conservação da Biodiversidade. Informe Nacional sobre as Areas Protegidas no Brasil. Brasília: MMA, 2007b. Disponível em: <http://www.mma.gov.br/estruturas/sbf2008 dap/ publicacao/149 publicaca015122008105137.pdf>. Acesso em: 31 jul. 2008.

BRASIL. Ministério do Meio Ambiente. Instituto Chico Mendes de Conservação da Biodiversidade. Ministério do Turismo. Turismo nos parques. Brasília: MMA, 2008. Disponível em: <http://www.mma.gov.br/estruturas/sbf2008 dap/ publicacao/149 publicacao15122008103259.pdf>. Acesso em: 20 jun. 2009.

CASCINO, F. Do turismo convencional ao ecolazer: análise dos fundamentos éticos e estéticos do lazer associado à natureza. CEDEC: debates socio ambientais, ano III, n9, p. 08-10, mar./jun., 1998.

CORNELL, J. Brincar e aprender com a natureza: um guia sobre a natureza para pais e professores. São Paulo: Companhia Melhoramentos: Editora SENAC São Paulo, 1996.

A alegria de brincar com a natureza: atividades na natureza para todas as idades. São Paulo: Companhia Melhoramentos: Editora SENAC São Paulo, 1997.

Vivências com a natureza: guia de atividades para pais e educadores. São Paulo: Aquariana, 2005.

Vivências com a natureza 2: novas atividades para pais e educadores. São Paulo: Aquariana, 2008. 
DIAS, G.F. A Educação Ambiental: valores humanos e estilos de vida sustentáveis. Boletim Informativo: desenvolvimento urbano e meio ambiente, ano 2, n.11, p. 0203, jul./ago. 1993.

DIAS, G.F. Educação Ambiental: princípios e práticas. 6. ed. São Paulo: Gaia, 2000.

FENNELL, D. Ecoturismo: uma introdução. São Paulo: Contexto, 2002.

FURIHATA, S.I. O desafio do movimento Sharing Nature na Educação Ambiental contemporânea. In: MINISTÉRIO DO MEIO AMBIENTE. MINISTÉRIO DA EDUCAÇÃO. O desafio do movimento Sharing Nature na Educação Ambiental contemporânea. Série Documentos Técnicos. Brasília: Órgão Gestor da Política Nacional de Educação Ambiental, 2006, p. 09-15.

INSTITUTO ROMÃ. Quem somos. Disponível em: <http://www.institutoroma.org.br>. Acesso em: 11 mai. 2008a.

INSTITUTO ROMÃ. Fundamentos. Disponível em: <http://www.institutoroma.org.br>. Acesso em: 04 set. 2008b.

MARCONI, M.A.; LAKATOS, E.M. Metodologia científica. São Paulo: Atlas, 2004.

MEDEIROS, R. Evolução das tipologias e categorias de áreas protegidas no Brasil. Revista Ambiente e Sociedade, Campinas, v.9, n.1, p. 41-64. Jan./Jun. 2006. Disponível em: <http://www.scielo.br/pdf/asoc/v9n1/a03v9n1.pdf>. Acesso em: 07 jul. 2009. ISSN: 1414-753X.

MENDONÇA, R. A experiência na natureza segundo Joseph Cornell. In: SERRANO, Célia (Org.). A educação pelas pedras: ecoturismo e Educação Ambiental. São Paulo: Chronos, 2000, p. 135-154.

A proposta da Sharing Nature do Brasil. In: MINISTÉRIO DO MEIO AMBIENTE. MINISTÉRIO DA EDUCAÇÃO. O desafio do movimento Sharing Nature na Educação Ambiental contemporânea. Série Documentos Técnicos. Brasília: Órgão Gestor da Política Nacional de Educação Ambiental, 2006, p. 16-20.

MILANO, M.S. Planejamento de Unidades de Conservação: um meio e não um fim. In: CONGRESSO BRASILEIRO DE UNIDADES DE CONSERVAÇÃO, I, 1997, Curitiba Paraná. Anais... Curitiba: Unilivre, vol. I, 1997, p. 150-165. 
OMT - Organização Mundial do Turismo. Guia de desenvolvimento do turismo sustentável. Porto Alegre: Bookman, 2003.

PIRES, P.S. Dimensões do ecoturismo. São Paulo: SENAC, 2002.

RAMOS, M. Aventura e turismo de aventura: faces mutantes. In: TRIGO, Luiz G. G. (Edit.) Análises regionais e globais do turismo brasileiro. São Paulo: ROCA, 2005, p. 469-479.

RICHARDSON, R.J. Pesquisa social: métodos e técnicas. São Paulo: Atlas, 1999.

RODRIGUES, .A. Ecoturismo: limites do eco e da ética. In: RODRIGUES, .A. (Org.). Ecoturismo no Brasil: possibilidades e limites. São Paulo: Contexto, 2003, p. 29-45.

SATO, M. Educação Ambiental. São Carlos: Rima, 2002.

SERRANO, C. A educação pelas pedras: uma introdução. In: SERRANO, C. (Org.). A educação pelas pedras: ecoturismo e Educação Ambiental. São Paulo: Chronos, 2000a, p. 07-24.

SHARING NATURE FOUNDATION. Country Coordinators. Disponível em: <http:// www.sharingnature.com/CountryCoordinators.html>. Acesso em: 09 nov. 2008c (tradução nossa).

. Flow learning ${ }^{\mathrm{TM}}$. Disponível em: <http://www.sharingnature.com/ FlowLearning.html>. Acesso em: 09 nov. 2008b (tradução nossa).

Sharing Nature Foundation. Disponível em: <http:// www.sharingnature.com>. Acesso em: 09 nov. 2008a (tradução nossa).

TAKAHASHI, L.Y. et al. Uso público em Unidades de Conservação. In: CONGRESSO BRASILEIRO DE UNIDADES DE CONSERVAÇÃO, I, 1997, Curitiba - Paraná. Anais... Curitiba: Unilivre, vol. I, 1997, p. 587-594.

TAKAHASHI, L.Y. Uso público em Unidades de Conservação. Cadernos de conservação, Curitiba, v.2, n.2, 2004. 40 p. 
NOTAS:

${ }^{1}$ Artigo apresentado com recursos fornecidos pela Fundunesp - Fundação para o Desenvolvimento da Unesp.

${ }^{2}$ Educador participante da $10^{\circ}$ Oficina de Formação de Educadores Multiplicadores do Aprendizado Seqüencial (julho 2007) promovida pela Associação Brasileira de Vivências com a Natureza - Instituto Romã.

${ }^{3}$ Medeiros (2006) analisa a trajetória e a evolução dos principais instrumentos políticos utilizados para proteção, criação e implantação das áreas naturais protegidas no Brasil, ao longo de seu período republicano, chegando a conclusão de que o SNUC, apesar de suas falhas, representa um inegável avanço a consolidação das áreas naturais brasileiras.

${ }^{4}$ Apesar de mencionar o termo turismo ecológico esta produção indispõe do intuito de estabelecer significativas distinções acerca da segmentação de turismo em áreas naturais e de suas conseqüentes classificações (turismo de natureza, ecoturismo e turismo de aventura) como propõem Fennel (2002) e Ramos (2005).

${ }^{5}$ As atividades turísticas realizadas em áreas naturais estão inseridas no contexto da segmentação turística representada pela classificação / tipologia de ecoturismo, sendo uma rotulação ampla e indiscriminada, uma espécie de idéia 'guarda-chuva', para contemplar um conjunto variado e pouco definido de atividades e de atitudes relacionadas ao turismo e aos ambientes naturais conservados. Nesse sentido, pode-se descrever as seguintes atividades inseridas nesse contexto: caminhada, mergulho, canoagem e rafting, voo livre, rappel, canionismo e cachoeirismo, montanhismo e escala, ciclismo, espeleologia, cavalgadas, acampamento, entre outras (BRASIL, 2006; PIRES, 2002; SERRANO, 2000).

${ }^{6}$ Termo traduzido do inglês Flow Learning e utilizado até o presente momento para representar o denominado 'fluxo de aprendizado'.

${ }^{7}$ Normalmente dirigida pela presença e atuação de um educador na natureza, que tenha como princípios: ensinar menos e compartilhar mais; ser receptivo e sensível; concentrar a atenção dos participantes; observar e sentir primeiro e falar depois; e criar um clima de alegria que prevaleça durante toda a experiência (CORNELL, 1996 e 2005). 
Vivências com a natureza: uma proposta de Educação Ambiental para o uso público em Unidades de Conservação

Fernando Protti Bueno: Universidade Estadual Paulista Julio Mesquita Filho, Câmpus Rosana (UNESP)

Email: fernando@rosana.unesp.br

Link para o currículo Lattes: http://lattes.cnpq.br/2008211573437117

Data de submissão: 01 de novembro de 2009.

Data do aceite: 12 de dezembro de 2009. 